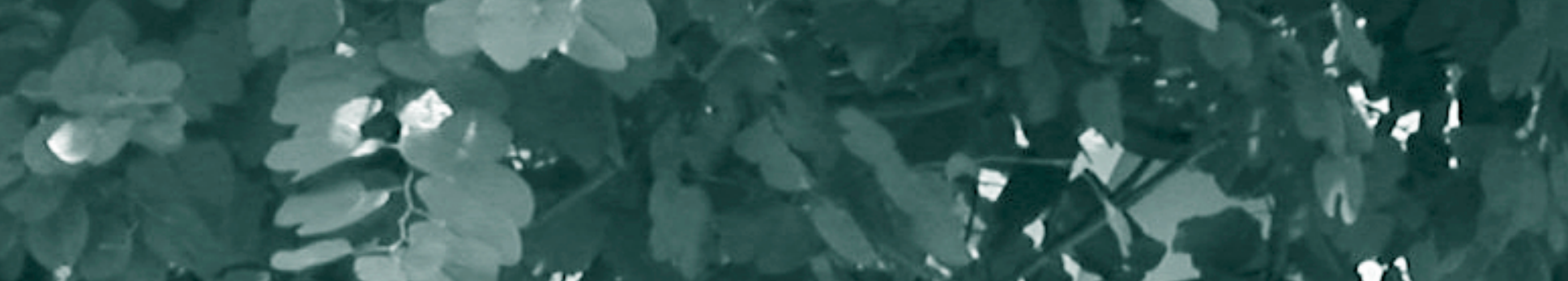

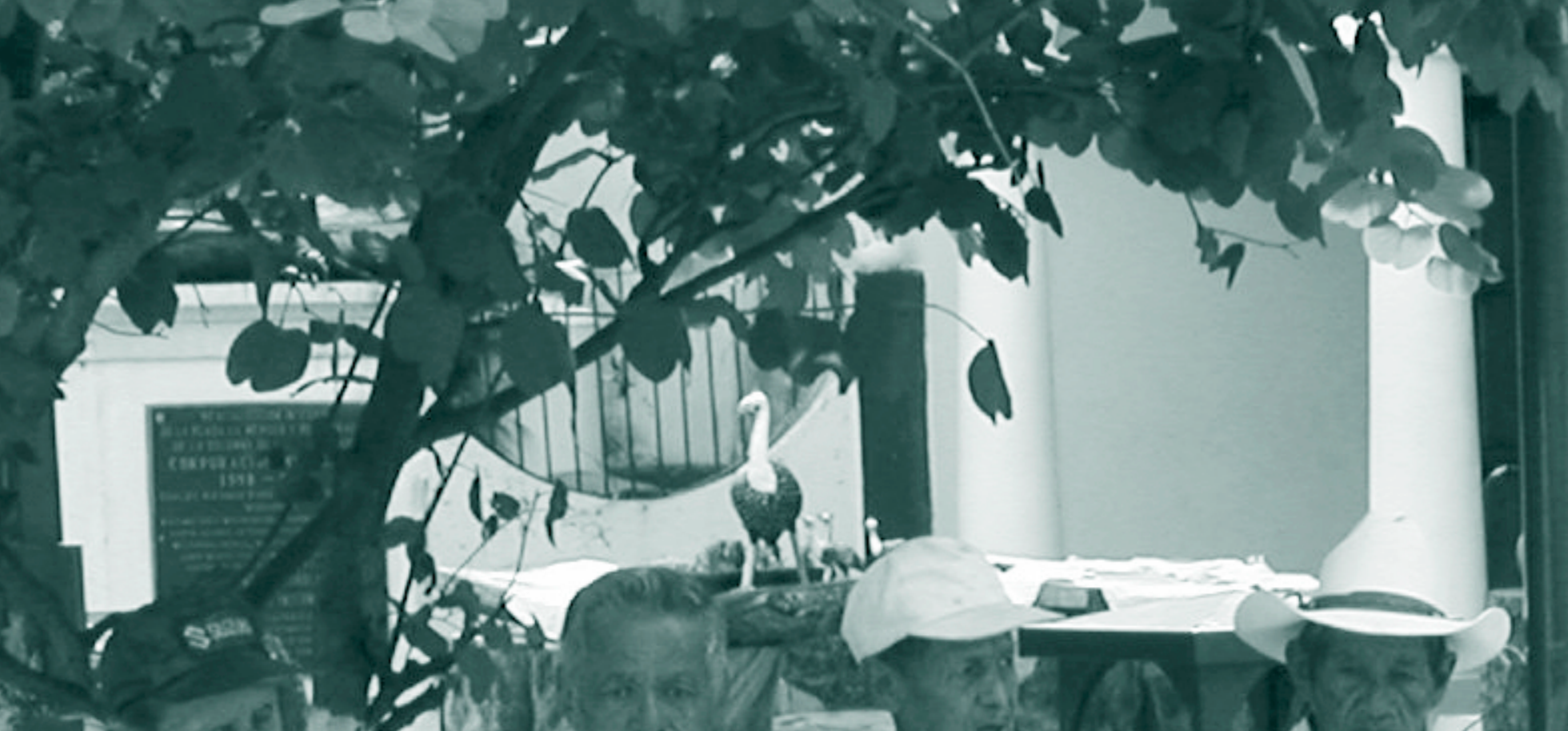

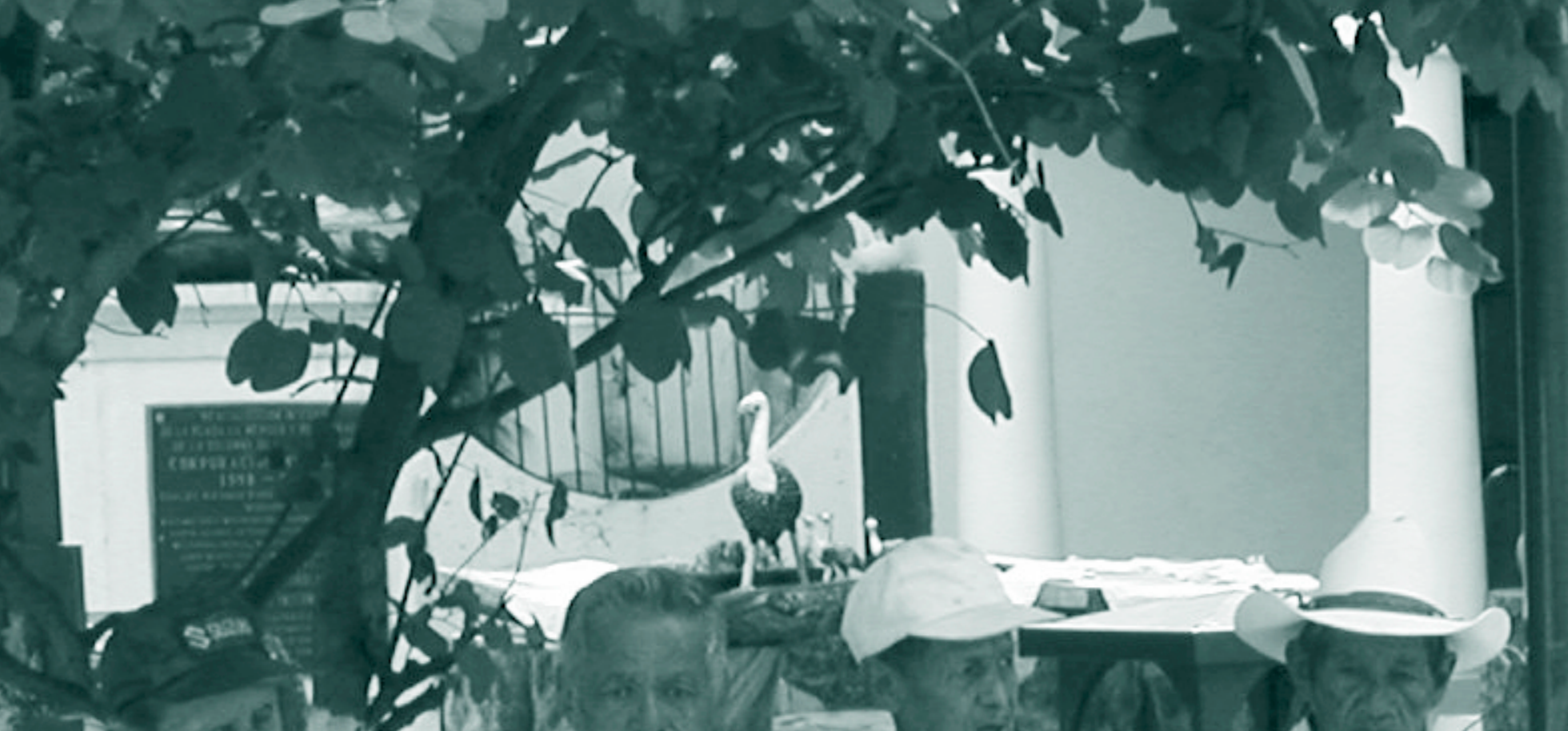

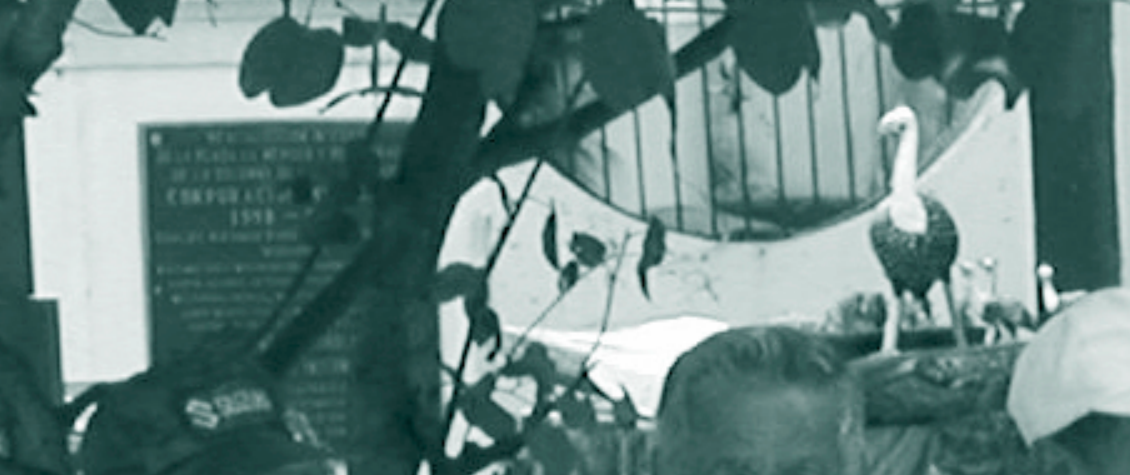

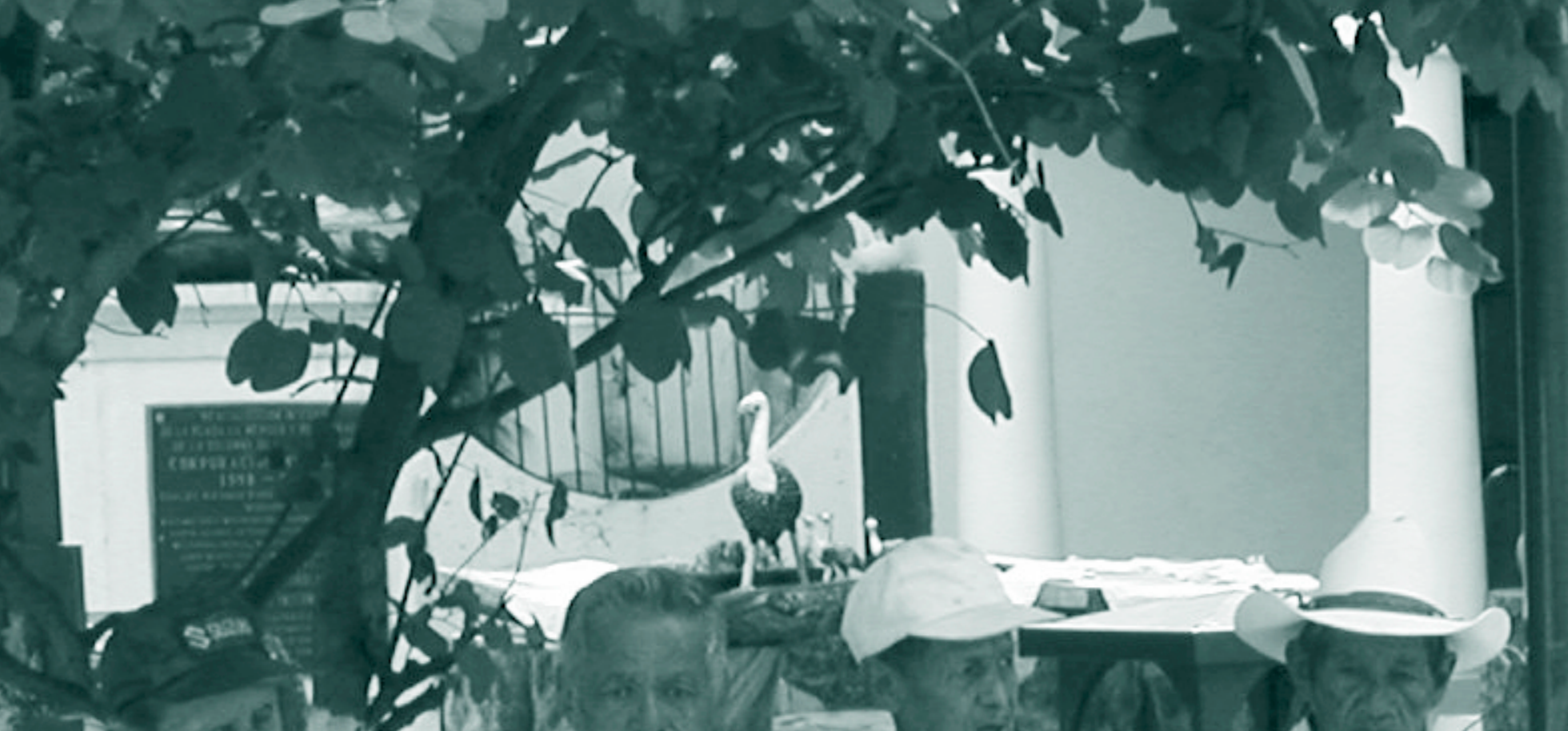

a.

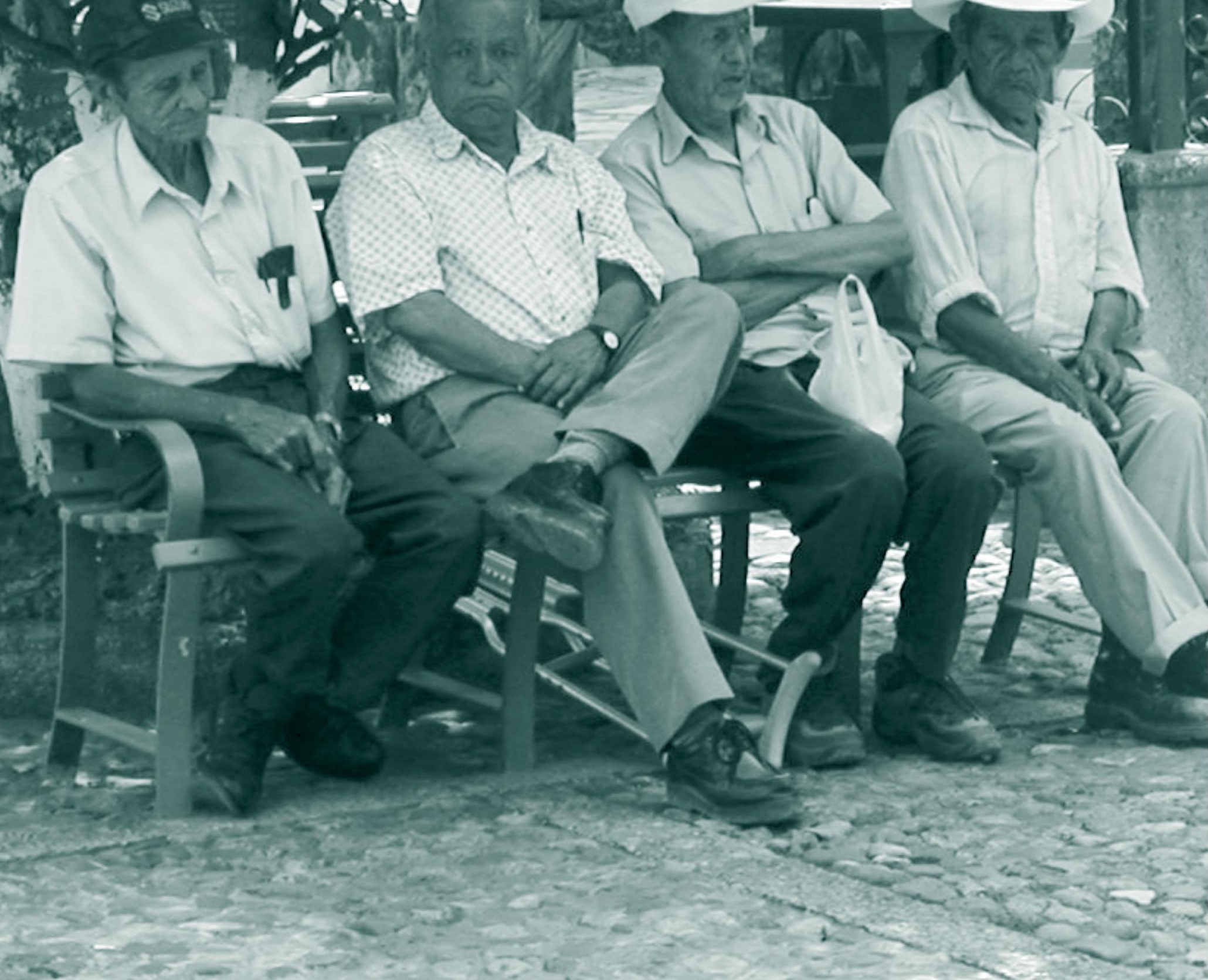




\section{1 argonautas y caminantes}

Augusto Serrano López

$\mathrm{N}$ ace esta revista para hablarnos del ser humano. Para hablar científicamente del ser humano, que de eso se trata en Demografía, U na disciplina científica que se ha hecho de métodos, procedimientos y técnicas de mucho calado y rigor. Pero, también, una disciplina que, como la naciente Ecología y por mor de su especificidad, trabaja en fronteras en las que puede desdibujarse el ser humano y aparecer desnudo y sin las notas que lo definen como especie.

Porque el ser humano, complejidad de complejidades, viene caminando por este mundo desde hace bastantes milenios y arrastra consigo, más allá de los números, una densidad cultural que conviene no dejar de lado, si es que pretendemos entenderlo y entendernos. El ser que, desde sus orígenes, no ha cesado de vagar en busca de lo que considerara lo mejor para vivir. C aminar que ha querido ser protocolado en libros de aventuras y libros de viajes.

Libros de viajes, salidas de la casa paterna, de los lares conocidos, de las calles familiares, del pueblo, de la ciudad que te vio nacer, de tu terruño, de tu patria si el viaje va de veras. H ojas escritas que te hacen volar por encima de las fronteras. Salidas como la de U lises, como la de $\mathrm{G}$ ilgamesh, como la de los $\mathrm{A}$ rgonautas, como la de $\mathrm{M}$ arco Polo, como la de A Ivar N úñez C abeza de $\mathrm{V}$ aca, como la de quienes conquistaron los polos de la Tierra o escalaron los ochomiles del H imalaya o las cumbres de los A ndes. Recorridos en busca de la fuente de la eterna juventud, de Jauja y el Dorado don de se bañan en oro, del Paraíso Terrenal que debe de estar en la cima de la más alta cumbre de A mérica, una que tiene forma de teta; búsqueda de las Siete Ciudades perdidas, la de esa isla de san Barandán que nunca está quieta, la de las minas del rey Salomón cuidadas por hormigas gigantes, la de los secretos horarios del globo para ver dónde poner el ritmo del tiempo, siguiendo la ruta del capitán Cook; aventuras por la consecución de las especias como la del loco de Colón que quería toparse con el G ran Kan yendo por el oeste o los viajes de los grandes coleccionistas de las especies de animales y plantas como los de Darwin, el de $\mathrm{H}$ umboldt o el de Celestino M utis y el de M alaspina; viajes imaginarios como el de San Juan de la Cruz perdido en la noche oscura del alma y reales como el del A polo que nos arrebató de una vez para siempre los sueños sobre la Luna. Viajes que redondearon el globo como el de $\mathrm{M}$ agallanes y EI C ano. G ente que va y viene sin parar, como si la Tierra propiciara con su redondez este ininterrumpido deseo de seguir siempre más allá, en busca de cualquier cosa, en busca de lo que es diferente y por eso cautiva y atrae y en busca del otro cuanto más extraño y exótico mejor, que así se suelen justificar los largos viajes, esos de los que se vuelve con las alforjas Ilenas de nuevas, de nuevos asuntos para ir dándole contenido a los relatos, quitán dole aburrimiento a la vida y completando el mapamundi de la Tierra. ¡Q ué más da, si el viaje lo fue de la fantasía hecho por semidioses o si lo realizaron seres humanos mortales! El viaje va siempre a al guna parte, por muy desorientado que parezca. A sí comenzó la vida, quizás con el renacuajo que inició un viaje desde el mar a la tierra y se atrevió a plantarle cara al oxígeno y a los rayos inmisericordes del sol. A sí comenzó la vida humana en viaje desde la selva hacia las sabanas cruzando las zacateras en busca de al imento. A sí se irguieron nuestros antepasados, cuando emprendieron desde Á frica un viaje fundador de pueblos que aún no termina. Somos gente en camino, buscadores de regiones apartadas, soñadores de espacios inéditos, viajeros eternos.

Pero el camino es, como la superficie de la esfera, la del redondo mundo que habitamos, infinito $y$, de trecho en trecho, hay que tomar descanso. Las gentes se asientan en lugares propicios para el despliegue de la vida humana, crean ciudades, inventan modos de 
convivencia civilizada, desarrollan culturas de todo tipo de acuerdo a las circunstancias y van moldean do así eso que llamamos la humanidad, la sociedad humana.

Es el sino de las poblaciones de la Tierra, de la Tierra con mayúscula, el único planeta del que, por ahora, disponemos.

Por eso es tan decisivo el estudio de las poblaciones para conocer lo que somos, de dónde venimos, y lo que de nosotros se puede esperar. Pero también, por eso mismo, la ciencia que trata de estos asuntos, la Demografía, no puede sino reflejar la gran complejidad que su asunto reclama. Complejidad que en modo al guno puede ser captada exclusi vamente con las técnicas matemáticas de la estadís- tica, por mucho que estas técnicas resulten imprescindibles y de un valor incalculable. Ciencia de las poblaciones humanas, donde el calificativo de humanas reclama estudios multidisciplinares de notable envergadura, pues lo que esta ciencia nos debe dar va mucho más allá de los meros mapas de distribución poblacional o de los índices demográficos sobre la movilidad de las poblaciones.

A hí están las dos dimensiones que yo creo son fundamentales y, yo diría, constituyentes de la especie humana: Ias eternas migraciones generadoras de ricos mestizajes y los asentamientos humanos, generadores de vida ciudadana y de civilización. 